\title{
Storytelling And Reflective Pedagogy: Transforming Nursing Education Through Faculty Development
}

Candice Phillips, Chamberlain College of Nursing, USA

Kellie Bassell, Chamberlain College of Nursing, USA

Laura Fillmore, Chamberlain College of Nursing, USA

\begin{abstract}
Nurse educators require pedagogical approaches beyond traditional methods to facilitate student learning of new competencies to practice in complex health care environments. However, little direction is available about how to effectively transform education. The purpose of this quality improvement project was to develop and implement steps to initiate change in both systems and processes of teaching and learning; to provide an efficient, sustainable method to incorporate transformative pedagogies through innovative faculty development; and, to collect outcomes of an eLearning course to support teaching, using Kirkpatrick's 4-level Model. An innovative course using storytelling and reflective pedagogy was developed to guide faculty into a transformative learning experience to challenge assumptions, gather insights, and raise questions about teaching practices. Pre- and post-course surveys captured data across three levels: satisfaction, knowledge and skill acquisition, and change in behavior. Forty-five participants were initially evaluated, while 31 were eligible for evaluation at three months. Follow-up survey results yielded a $42 \%$ response rate. Pre-and post-surveys were analyzed using a two-tailed, dependent $t$-test. Significant gains were recorded across all three areas $(p<0.05)$, with large to medium effect size noted using Cohen's $d$. Follow-up surveys revealed a significant change in knowledge $(p<0.05)$, whereas the skill and attitude effect change were not statistically significant $(p<0.05)$. Results suggest storytelling and reflective pedagogy are effective for faculty to confront and resolve actual and desired teaching practices, and that faculty placed value on reflection to facilitate self-awareness, question assumptions, and nurture ideas about personal and professional growth.
\end{abstract}

Keywords: Nursing; Faculty Development; Pedagogy; e-Learning

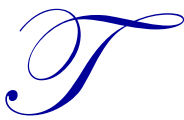

he urgent call to transform educational practice rings loud across higher educational landscapes (Cohen \& Kisker, 2010; Hutchings, Huber, \& Ciccone, 2011). However, transcending boundaries of knowledge development requires a paradigm shift in the way educators view student learning (Bain, 2004; Bass, 2012; National Research Council, 2000). Accordingly, the National Academy of Medicine, formerly known as the Institute of Medicine (IOM, 2003), declared transformation of education an imperative to equip health professionals with necessary competencies to deliver safe, evidence-based, patient-centered care. In 2010, landmark reports from the Carnegie Foundation for the Advancement of Teaching (Benner, Sutphen, Leonard, \& Day, 2010) and the IOM task force on the Future of Nursing charged nurse educators with using new competencies in preparing future nurses to practice in increasingly complex health care environments. In 2014, the Robert Wood Johnson Foundation requested the IOM to assemble a committee to review progress made on implementing The Future of Nursing report recommendations. Findings identified continuing need for effective education in preparing nurses, who represent the largest segment of the health care profession, to provide quality health care in a system that is changing both rapidly and fundamentally. Certainly, the current health care landscape makes the delivery of quality nursing education more important than ever (National Academies of Sciences, Engineering, and Medicine, 2015).

Advancing nursing education requires qualified nurse educators to bring state-of-the-science knowledge of nursing practice to the academic setting. However, the critical shortage of nursing faculty has necessitated a quick-hire process of expert clinicians with little orientation to the teaching and learning process (AACN, 2014). Additionally, new ways of teaching are needed to graduate nurses who are agile in complex decision-making, can easily adjust to a changing 
health care landscape, and are able to think critically while caring for diverse patient populations. Indeed, faculty need pedagogical approaches beyond traditional methods to facilitate student learning of new competencies, while creating an active and participatory educational environment aligned with the realities of today's nursing practice (Benner et al., 2010; Sherwood \& Horton-Deutsch, 2015).

No longer can filters from past experience and education be used to view present and future educational needs. Nursing must transform education and practice to adjust to the changing health care environment, yet little direction is available about how to effectively respond to the confusion and rapid acceleration of required change (Sherwood \& HortonDeutsch, 2015). Need for evidence-based pedagogies is well documented in nursing literature (Halstead, 2007; Benner et al., 2010), but process steps that lead to desired change remain unknown (Sherwood \& Horton-Deutsch, 2015). Additionally, the complexity of the education system, and the influences that act upon it, both internal and external, make implementation of improvements difficult to sustain. Therefore, many nursing programs struggle to initiate change without an efficient, structured method for implementing effective pedagogies necessary for the continually transforming health care environment.

The purpose of this quality improvement project was threefold: first, to develop and implement a series of thoughtfully crafted steps to initiate change in both systems and processes of teaching and learning in our nursing program; second, to provide an efficient, sustainable method to incorporate transformative pedagogies through innovative faculty development; and, third, to collect self-reported low- and high-level outcomes of an online interactive faculty development course to support teaching using Kirkpatrick's 4-level model. To this end, we established an infrastructure and culture to support an eLearning program of faculty development, and then implemented storytelling and reflective pedagogy as an educational change strategy to lead and sustain transformation in teaching nursing. Although transforming nursing education is a daunting task, our hope is to inspire those who are involved in, or contemplating, change to seek effective solutions from those who have begun the journey.

\section{BACKGROUND}

Change is hard; both to implement and to sustain. An organization will likely return to its "norm" or previous state unless a supportive, stable infrastructure is present. Infrastructural components facilitate integrated development of the desired initiative, creating shared responsibility for implementing and sustaining change (Sabelli \& Dede, 2013). Accordingly, an important first step in transforming education is to create an infrastructure to support change. This involves a shift from a traditional organization to a more transformative one that focuses on improvement of teaching practice through integration of new competencies and advances in education (Sherwood \& Horton-Deutsch, 2015). Changing perceptions across any organization is key to effective change; placing emphasis on faculty development is especially important in supporting faculty members to adapt to their changing roles in nursing education (Sarikaya, Kalaca, Yegen, \& Cali, 2010).

Also important to initiating and sustaining successful change in educational reform is the establishment of collegewide communication and collaboration (Schriner et al., 2010). Aligning faculty, leaders, and faculty developers in a collaborative vision with the strategic direction of the institution is fundamental to achieve educational transformation (Neal \&Peed-Neal, 2010). Efforts to support and guide faculty development - particularly in a changing context - are critically important for advancing scholarly competence. Faculty developers bring stakeholders together to strategize and collaborate on an organizational level to promote effective teaching and learning, while developing the capacity of individual faculty members (Schroeder, 2011). A supportive, stable infrastructure is vital to systemic educational improvements. Attention to infrastructural needs support their evolution over time, leading to sustained improvements. Faculty development ultimately boosts student achievement, increasing overall institutional effectiveness and transforming learning through new and improved ways of teaching nursing (Sarikaya, Kalaca, Yegen, \& Cali, 2010).

Another step in transforming education is formation of an organizational culture that supports scholarly teaching and facilitates socialization and role development for nurse educators. Culture change depends upon the definition and view of the culture by its group members (Jasimuddin \& Hasan, 2015). Shared values, beliefs, and norms shape culture and influence change within the nursing program for successful implementation of new practices. Faculty developers facilitate change and improve organizational culture through enhancing scholarly practices of evidence-based teaching and learning (Schroeder, 2011). Through structured faculty development, internalizing beliefs, values, and attitudes 
toward teaching is championed, promoting formation of identity of faculty as excellent nurse educators. Explicitly promoting a culture of teaching excellence across the nursing program can have a positive and sustained impact on individual and collective teaching practices, and on student success outcomes (Halstead, 2009; McLaughlin, 2009). The resulting transformation of both faculty member and student represents a paradigm shift away from the traditional faculty-centered philosophy that steered the delivery of educational content, toward a model of student-centered learning that encourages students to seek and apply knowledge in new ways that develop critical thinking and problemsolving skills (Schaefer \& Zygmont, 2003)

In today's changing health care landscape, transformation must be the cornerstone of nursing and nursing education. Transforming learning is requisite to transformative practice which requires new ways of teaching (McComish \& Parson, 2013). However, nursing programs must be equipped to initiate and sustain teaching competency in order to prevent a return to previous, unsuccessful teaching methods. Faculty developers can be highly effective in motivating faculty to move beyond normally prescribed roles; their mobilizing influence is helpful in encouraging faculty to continuously seek improvement and contribute to innovative ideas, processes, and practices. In this way, faculty developers play a crucial role in facilitating change and integrating a culture of teaching excellence into the life of the nursing program.

\section{INTENDED IMPROVEMENT: TRANSFORM TEACHING PRACTICE THROUGH INNOVATIVE, E-LEARNING FACULTY DEVELOPMENT USING STORYTELLING AND REFLECTIVE PEDAGOGY}

To respond to calls for academic reform in nursing education, our nursing program established a structured faculty development program to lead organizational change in building an intentional, educational culture of teaching excellence. A strategic five-year faculty development plan was developed to support and guide faculty to reflect on, and effectively use, evidence-based pedagogies to successfully facilitate student achievement of course and program outcomes. Integral to the faculty development plan was the opportunity for faculty to challenge perceptions and gather insights about influences on their teaching practice. The goal was for faculty to learn about themselves as teachers, develop expertise in asking good questions about how teaching practice connects with student learning, and use the information gathered to improve teaching practice. To that end, an innovative, e-Learning interactive course was developed, implemented, and tested to enhance understanding of the teaching and learning process and teaching effectiveness..

Storytelling and reflective pedagogy were used to guide faculty into a transformative learning experience to challenge assumptions, gather insights, and raise questions about their teaching practices. Storytelling was selected to help faculty suspend belief, pique their curiosity, and guide them into a new way of teaching. Storytelling is a fundamental part of life. It is a philosophically provocative and practically useful way to make meaning, linking curiosity with experience across the gap of the unknown. The probing context of stories told in new ways helps faculty to make sense of abstract complexities, rendering it an unexpected but effective medium to explore new ways of teaching. According to McDrury and Alterio (2003), when we tell stories and use reflection, the possibility for change in ourselves and others is created.

As a pedagogy, reflection is a systematic way of thinking about one's actions and responses (Sherwood, 2014). It is a change process that incorporates experiential learning by considering what one knows, believes, and values within the context of an event, discriminating among emotional reactions and using the information to guide future responses and actions. In this way, reflection provides a mirror to the self by helping faculty to confront and resolve actual and desired teaching practices (Sherwood \& Horton-Deutsch, 2012). Indeed, reflection is an educational change strategy that promotes a spirit of inquiry that can be used for self-development, and for determining future actions and responses in the academic role (Sherwood \& Horton-Deutsch, 2012).

Professional development requires moving beyond acquisition of new knowledge and understanding into questioning and transforming our assumptions, values, and perspectives (Sherwood \& Horton-Deutsch, 2012). The pedagogies of storytelling and reflection, used in innovative ways, offered the means to transformation - to a change in attitudes, skills, and behaviors related to teaching.

In collaboration with the instructional designer, faculty developers wrote stories of individuation that would appeal across multiple genres and depicted these stories as graphic novels in an online format. Individuation is a term used 
by C.G. Jung (1969) for the process of psychic integration through which an individual finds a deep, inner relationship with self. According to Jung, individuation encompasses self-actualization, personal development, and value fulfillment. Through accessing and receiving the symbolic contents of a well-known individuation story, and by critically analyzing its underlying premises, faculty were provided the opportunity to challenge their perceptions and gather insights about influences on their teaching practice, while deepening their self-awareness.

One story involved a superhero called Captain Chamberlain, Master Instructor (See Figure 1).

Figure 1. Captain Chamberlain

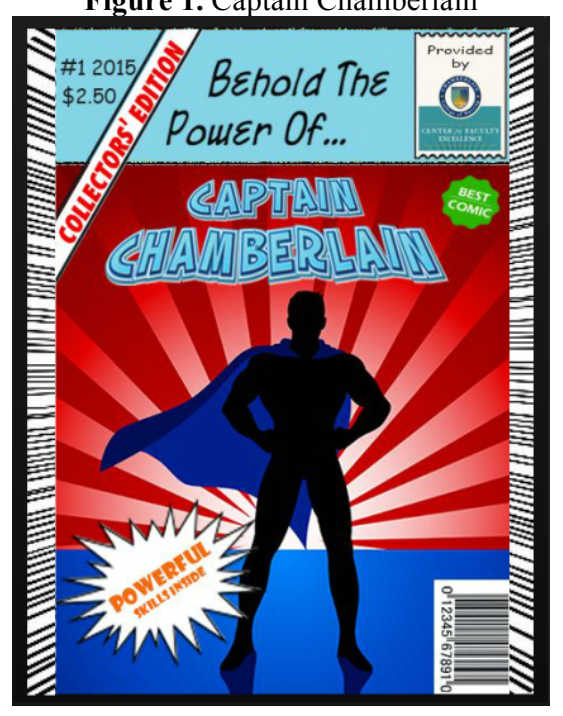

In the story, Captain Chamberlain begins as an ordinary educator, Peter Professor, who teaches as he has been taught until he discovers his superpowers or new ways of teaching. On his journey of discovery, Peter encounters his nemeses--fellow educators who focus on content, grades, and right answers as integral to teaching. Peter is determined not to succumb to these old ways of teaching but becomes overwhelmed by learning new methods. Just when he fears he cannot succeed in learning effective ways of teaching, he encounters a master teacher who helps him to take down old paradigms and create new ways of thinking through intellectual challenge. Peter emerges from his ordeal with insight, awareness, and superpowers needed for deepening student learning across learning environments.

In addition to Captain Chamberlain, the well-known children's story, Alice in Wonderland, was adapted using similar themes as in the Captain Chamberlain story. Two stories, similar in thematic content but different in genre, were provided to appeal to varied preferences. Faculty were encouraged to read the story that most captured their imagination.

In both stories, each turn in the narrative arc provides insight into the underpinnings of teaching, and exposes incongruities between teaching actions and assumptions. Shadiow (2013) asserts that paying attention to thoughts and feelings surrounding this process illuminates how assumptions come to be confirmed, countered, or revised, and how teaching can be transformed for the better. Storytelling makes opportunities for growth become visible, revealing new perceptions that were not expected. It is within this moment of surprise or wonderment, she claims, that the potential for deeper understanding and growth emerges.

After reading the story, faculty then reflected upon the deeper meaning of the story using an e-Learning interactive journal which guided them to ask questions, challenge assumptions, and invesitgate their teaching practice (See Figure 2). 
Figure 2. Captain Chamberlain Reflective Journal

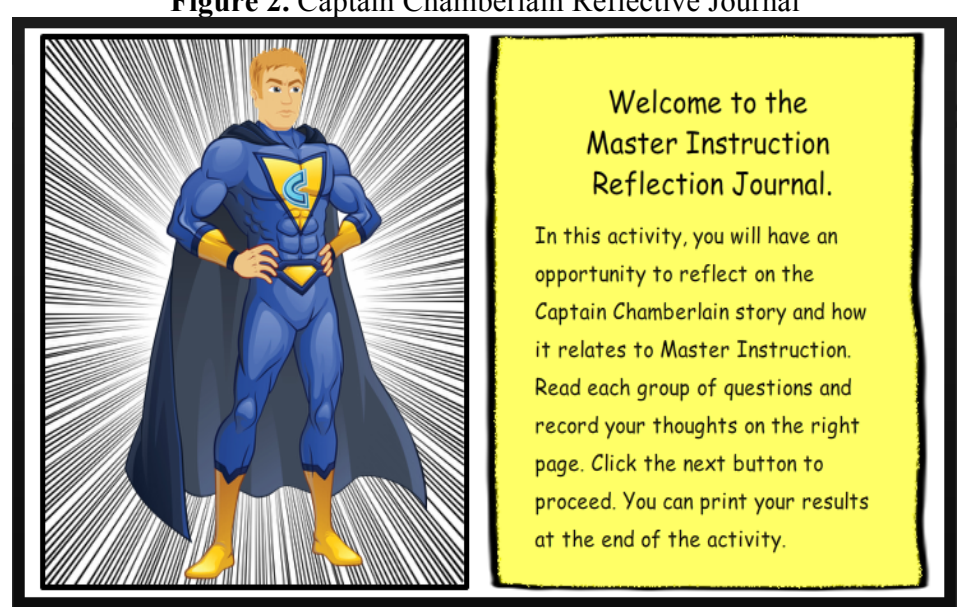

Sherwood \& Horton-Deutsch (2012) suggest that the questioning aspects of reflection builds an enviornment that nurtures ideas and makes thinking visible. Through critical reflection, faculty were guided to become increasingly aware of the expectations, values, and underlying beliefs that frame how they teach, and to grow into new understandings about the enterprise of teaching. Shadiow (2013) contends that commitment to strengthening teaching grows in proportion to one's understanding of it; as insights deepen, possibilities multiply. This commitment is fed by the wellspring of stories, suggests Shadiow (2013), no matter the discipline. Seeking these deepest levels of reflection guided faculty to better understand their teaching and strengthen their practice, effecting an even greater potential for transformation.

\section{THEORETICAL FRAMEWORK: KIRKPATRICK'S 4-LEVEL MODEL FOR EFFECTIVENESS OF PROFESSIONAL DEVELOPMENT}

A strategic evaluation plan based on Kirkpatrick's Model (1994) was employed to measure outcomes of our faculty development e-Learning interactive course. Kirkpatrick's hierarchy model is widely used in health professions education, including nursing, to determine the effectiveness of faculty development (Leslie, Baker, Egan-Lee, Esdalie, \& Reeves, 2013; Opperman, Liebig, Bowling, Johnson, \& Harper, 2016; Zeng, Bender, and Nadershahi,2015). In this model, outcomes of professional development programs are evaluated using four levels: learner satisfaction, knowledge and skill acquisition, application of new knowledge and skills, and the achievement of mission-critical goals. This 4-level model of evaluation ensures continuous quality improvement of faculty development offerings, maximizes transfer of learning to behavior change in faculty, and contributes to key organizational outcomes. By gathering data demonstrating effectiveness of professional development resources, faculty developers can credibly show the value that professional development resources bring to the institution.

Many health professions report only low-level outcomes focused on learner satisfaction (Dreyer, Couper, Bailey, Talib, Ross,\& Sagay, 2015; Haji, Morin, \& Parker, 2013; Lapkin, Levett-Jones, \& Gilligan, 2015). Although learner satisfaction is important, higher-level outcomes aim at transfer of learning to behavior change in faculty, which provides greater insight into the effectiveness of professional development resources. For this reason, we evaluated and report levels 1, 2, and 3 outcomes adapted from Kirkpatrick's Model, including:

1. faculty satisfaction with the professional development program, including content, delivery methods, and structure;

2. faculty knowledge and skill acquisition, including self-reported improvement in understanding of content presented, ability to integrate the content into their practice and value of the content presented; and

3. direct application of newly acquired instructional strategies and tools in practice. 


\section{METHODOLOGY}

\section{Context}

Our nursing program is a large multistate, multiprogram, non-tenure institution in the United States. In keeping with its single mission, the College provides multiple points of entry for both graduate and undergraduate nursing students including: a pre-licensure BSN degree program on 20 campuses located in 14 states: a RN-BSN option that is offered in the online environment to registered nurses in 48 states; and seven specialty tracks for advanced nursing education. Approximately twenty-five percent of the student body is comprised of pre-licensure campus-based BSN students; the rest are enrolled in one of our post-licensure RN-BSN, MSN, or DNP programs. To maintain its student-centric focus, the College employs a cadre of diverse full- and part-time faculty.

\section{Planning}

An e-learning format was utilized to feature storytelling and reflective pedagogy to transform teaching practices. Faculty developers, in collaboration with an instructional designer, used Internet technologies to create, deliver, facilitate, and evaluate this e-Learning interactive course. The aim of this course was to guide faculty on a transformative journey to challenge assumptions and raise questions about teaching. This focus on faculty learning about learning was an intentional move from traditional, one-time faculty training toward ongoing, evidence-based professional development that places value and importance on reflection to enhance transfer of learning to the workplace (Steinert, 2014). To achieve this aim, an e-Learning, interactive course, including a graphic comic book and reflective journal, were developed to invite faculty to practice new skills in a compelling way. Situations and concepts that easily connect faculty with day-to-day teaching were graphically depicted creating a visual connection with the content, while e-Learning technology put learners in the position of discovering new information for themselves.

A virtual format was selected not only to transform static faculty training into interactive, engaging e-Learning, but also to provide efficiency and cost-effectiveness of delivery, as well as flexible framework (asynchronous) for anytime, anywhere self-guided learning. Equally important, this medium exposed faculty to latest educational technology and instructional methods, and fostered e-Learning competencies, which is critically important given the large numbers of our faculty who teach online.

Additionally, an electronic Facilitator's Guide was provided for academic leaders to facilitate team discussions about the experiences and insights encountered while completing the e-Learning, interactive course. Faculty can print and use their journal from the course as a basis for reflecting together with teams, thereby providing opportunity to gain insights, expand perspectives, and coordinate actions to accomplish change. Bringing thoughts and ideas to a collective process of reflection generates shared meanings; multiple views about teaching can be shared, and then used to transform individual teaching practices. According to Hutchings, Huber, \& Ciccone (2011) team reflection leads to transformational learning, fostered by inquiry and engagement. Supporting faculty in this way —as inquirers into their own teaching - creates a collaborative community around teaching. At our nursing program, team reflection is conducted face-to-face and/or virtually with both full- and part-time faculty members

\section{Design, Methods of Evaluation, and Sample}

This quality improvement project utilized a mixed methods design to examine the processes and outcomes of using an e-Learning interactive course to transform teaching practice through storytelling and reflective pedagogy. Utilizing Kirkpatrick's Model (1994), pre- and post-course surveys were developed to capture data across three identified levels: faculty satisfaction, faculty knowledge and skill acquisition, and a change in participant behavior, namely, to what degree does the faculty member apply what was learned on the job. These electronic surveys were embedded into the beginning and end of the e-Learning, interactive course, and instructions were provided for completion of the surveys.

The pre-course survey addressed faculty ratings of their knowledge, skills, and attitudes toward the course content, using a one group pre-and post-test design. This pre- course survey aligns with level 1 of Kirkpatrick's Model. The post-course survey addressed these same areas of knowledge, skills, and attitudes toward the e-Learning interactive 
content, using a one group post-test only design. Additionally, the post-course survey addressed participant reaction (satisfaction, engagement, and relevancy of content), as well as aspects of learning (confidence, and commitment), which align with levels 1 and 2 of the Kirkpatrick Model respectively.

Post-course surveys were employed longitudinally following three-month completion of the e-Learning interactive course to analyze a transfer of learning, namely, to what degree the faculty member applies what was learned during the course in their teaching practice. The electronic post-course survey link was distributed via email. This phase of evaluation aligns with level 3 of Kirkpatrick's Model.

\section{Analysis and Findings}

The initial sample size was 64 faculty participants. This constituted the number of full- and part-time faculty members who completed the e-Learning, interactive course using storytelling and reflective pedagogy within a specified threemonth timeframe. At the time of data analysis, 45 faculty participants were eligible to be evaluated for levels 1 and 2 of Kirkpatrick's Model, based on the completion of pre- and post-course surveys. However, only 31 faculty participants were eligible to be evaluated for level 3 outcomes, at three months completion of the course. Of the 31 faculty participants eligible for inclusion in the three-month analysis, 13 faculty participants responded culminating in a $42 \%$ response rate.

Descriptive and inferential analyses of the study sample were conducted. Descriptive statistics for all three surveys (pre-course, post-course, and three-month follow up) are presented in Table 1.

Table 1. Longitudinal Descriptive Statistics for Knowledge, Skills and Attitude

\begin{tabular}{l|c|c|c|c|c|c|c|c|c|}
\hline & \multicolumn{3}{|c|}{ Pre-course survey } & \multicolumn{3}{c|}{ Post-course survey } & \multicolumn{3}{c}{ Follow-up survey } \\
& M & SD & N & M & SD & N & M & SD & N \\
\hline Knowledge & 3.64 & 0.80 & 45 & 4.51 & 0.66 & 45 & 4.31 & 0.48 & 13 \\
\hline Skills & 3.80 & 0.81 & 45 & 4.40 & 0.72 & 45 & 4.54 & 0.52 & 13 \\
\hline Attitude & 4.53 & 0.69 & 45 & 4.89 & 0.31 & 45 & 4.77 & 0.60 & 13 \\
\hline
\end{tabular}

Note: $\mathrm{M}=$ mean. $\mathrm{SD}=$ standard deviation. $\mathrm{N}=$ sample size.

Inferential statistics included the use of t-tests and Cohen's $d$. The level of significance for the study was 0.05 . The pre- and post-course survey scores were analyzed using a two-tailed, dependent t-test. The knowledge effect was statistically significant, $\mathrm{t}(44)=2.015$, and $\mathrm{p}=0.3 .03 \mathrm{E}-09$, at an alpha level of 0.05 . The skill effect also was statistically significantly, $\mathrm{t}(44)=2.015$, and $\mathrm{p}=1.8 \mathrm{E}-05$, at an alpha level of 0.05 . Likewise, the attitude effect was statistically significant, $\mathrm{t}(44)=2.015$, and $\mathrm{p}=0.0003$, at an alpha level of 0.05 .

Further descriptive statistical analysis was performed using a Cohen's d to determine the effect size of the e-Learning, interactive course on participants' knowledge, skills, and attitudes. In regard to knowledge, Cohen's d = 1.19, which indicated a large impact of the e-Learning, interactive course on post-course survey scores. In regard to skill, Cohen's $\mathrm{d}=0.78$, which indicates a medium impact of the e-Learning, interactive course on post-test scores. Finally, in regard to attitude, Cohen's $d=0.67$ which indicates a medium impact of the e-Learning, interactive course on post-survey scores (Fritz, Morris \& Richler, 2012).

Follow-up surveys employed three months after completion of the e-Learning, interactive course were analyzed to determine whether the change in knowledge, skills and attitudes was sustained. Descriptive (see Table 1) and inferential analyses of the study sample were conducted comparing these results to the post-course surveys. Inferential statistics used included t-tests and Cohen's d. The level of significance for the study was 0.05 . The post-course, followup survey scores were analyzed using a two-tailed, dependent t-test. The knowledge effect was statistically significant, $\mathrm{t}(12)=2.18$, and $\mathrm{p}=0.02$, at an alpha level of 0.05 . However, the skill effect was not statistically significantly, $\mathrm{t}(12)$ $=2.18$, and $\mathrm{p}=0.44$, at an alpha level of 0.05 . Additionally, the attitude effect was also not statistically significant, $\mathrm{t}$ $(12)=2.18$, and $p=0.17$, at an alpha level of 0.05 .

The post-course survey results were also analyzed utilizing descriptive statistics for the six items delineated in Table 2 . 
Table 2. Descriptive Statistics for post-course survey items aligned with Kirkpatrick's Levels of Evaluation

\begin{tabular}{|l|c|c|c|c|}
\hline \multicolumn{1}{c}{$\begin{array}{c}\text { Kirkpatrick Level of } \\
\text { Evaluation }\end{array}$} & Post-course survey item & M & SD & N \\
\hline Level 1 - Reaction & Satisfaction & 4.53 & 0.63 & 45 \\
\hline & Expectations & 4.31 & 0.73 & 45 \\
\hline & Relevancy & 4.51 & 0.79 & 45 \\
\hline Level 2 - Learning & Engagement & 4.27 & 0.91 & 45 \\
\hline
\end{tabular}

Note: Note: $\mathrm{M}=$ mean. $\mathrm{SD}$ = standard deviation. $\mathrm{N}$ = sample size

\section{DISCUSSION}

To meet the threefold aim of this quality improvement project a supportive infrastructure and intentional educational culture to support an e-Learning program of faculty development was established at our nursing program. Regular and ongoing national faculty meetings, both onsite and virtual venues, were convened. A dedicated faculty portal web page was created to enable faculty from across all programs to access professional development resources. An advisory board was created to inform and sustain faculty development initiatives, and faculty leaders were united in ongoing virtual meetings to collaborate on teaching and learning issues, including socializing faculty, learning about available resources and support services, and establishing a collaborative vision in alignment with the strategic direction of the institution. In these monthly meetings, faculty leaders from across all campuses and programs meet to discuss emerging issues to support and enrich the life and work of faculty.

Following the development of a supportive infrastructure and culture to support teaching excellence, an e-Learning, interactive course using storytelling and reflective pedagogy was developed as an educational change strategy to lead and sustain transformation in teaching nursing. Findings suggest that the e-Learning, interactive course had positive impact on outcomes corresponding to Kirkpatrick's 4-level Model of evaluation of professional development effectiveness. Faculty participants reported satisfaction with the professional development program (level 1 outcomes), improved knowledge and skill acquisition (level 2 outcomes), and direct application of newly acquired instructional strategies and tools in practice at three months following course completion (level 3 outcomes). Results from implementation of this innovative course suggest that the process of storytelling and reflective pedagogy are effective for faculty to confront and resolve actual and desired teaching practices, and inspire faculty to be inquirers into their own teaching. Data revealed that faculty placed value on individual and collective reflection to facilitate self-awareness, question assumptions, and nurture ideas about personal and professional growth. Additionally, faculty participants report that using individual reflection enabled them to gain insights, expand perspectives, and plan actions to accomplish change.

These preliminary findings support previous research findings that structured, well-designed faculty development resources are well accepted by faculty and, importantly, catalyze transformation of teaching practice (Zheng, Bender, $\&$ Nadershahi, 2015). This quality improvement project contributes to literature in nursing and the health sciences regarding the capacity for faculty development to lead organizational change to transform teaching practice. Additionally, this project may provide guidance for other nursing and health science programs in designing and implementing innovative, e-Learning, interactive faculty development resources.

Limitations to the quality improvement project may impact findings. Although the initial sample size was 64 faculty participants, at the time of data analysis only 45 faculty participants were eligible to be evaluated for levels 1 and 2 of Kirkpatrick's Model, and only 31 faculty participants were eligible to be evaluated for level 3 outcomes. Of the 31 faculty participants eligible for inclusion in the three-month analysis, 13 faculty participants responded culminating in a $42 \%$ response rate. Despite the small sample size, a broad spectrum of nursing faculty were represented, including full-and part-time, graduate and undergraduate faculty. Additionally, this sample included faculty with a range of experience, from novice educators with less than two years of teaching to seasoned educators with more than 15 years of teaching. Another limitation is that level 4 outcomes were not analyzed at the time of data analysis. It is our plan to include analysis of End-of-Course Survey data for the courses taught by these participants to ascertain whether mission-critical outcomes were achieved. Indicators reviewed will include section mean course grade, section mean 
student satisfaction with the course, section mean student satisfaction with the faculty member, and the section mean student engagement index. This phase of evaluation aligns with Level 4 of Kirkpatrick's Model and will be implemented at the completion of the fiscal year in June, 2017.

\section{IMPLICATIONS}

Transformation must be the cornerstone of nursing and nursing education. Nurse educators must acquire needed teaching competencies to integrate current knowledge, trends, and technology advances into education (Felver et al., 2010; Forneris \& Fey, 2016). Structured faculty development is essential not only to develop, use, and test innovative teaching methods, such as storytelling and reflective pedagogy, to enhance clinical and classroom teaching, but also to lead organizational change in response to calls for academic reform. Faculty developers bring stakeholders together to strategize and collaborate on an organizational level, while developing the capacity of individual faculty members in a supportive culture. Implications for nursing education include strong support for innovative faculty development using storytelling and reflective pedagogy to create sustainable change in nursing academia that is grounded in theory and data.

Further research is needed to evaluate the effectiveness of using storytelling and reflective pedagogy to transform nursing education. Nursing programs are challenged to take the next step in the journey toward better and more effective methods of teaching nursing. In this context of rapidly evolving change, innovative faculty development is no longer optional if nursing education is to thrive and adapt in response to an ever-changing health care landscape.

\section{ACKNOWLEDGEMENTS}

We gratefully acknowledge the skill and talent of the Center for Faculty Excellence Instructional Designer, Stacie Sedlmayer, who creatively brings our faculty development initiatives to life.

\section{AUTHOR BIOGRAPHIES}

Candice Phillips, PhD, RN, APRN, CNM, CNE, is a Faculty Development Specialist at Chamberlain College of Nursing. Dr. Phillips brings her expertise in experiential learning, innovative teaching strategies, new pedagogies, and the delivery of content using educational technology to support formation of excellent educators. At Chamberlain and throughout the academic community, she is well regarded for her capacity to develop educators into engaged explorers of the teaching and learning process. Her presentations and publications address the role of faculty development in transforming nurse educators and leading organizational change. In addition to her work in academia, Dr. Phillips has many years of experience as a board-certified nurse midwife. Email: CPhillips2@chamberlain.edu

Dr. Bassell graduated from Boston College with a BSN and Florida Atlantic University with an MSN. She earned a doctorate in education, in curriculum \& instruction with a focus on educational technology, from the University of Florida. She has over 15 years of academic experience across a variety of settings. She has participated in the development and implementation of imaginative and creative strategies to promote and support change in faculty's understanding of the teaching/learning process. She is currently a Faculty Development Specialist at Chamberlain College of Nursing. Email: KBassell@,chamberlain.edu

Dr. Fillmore provides leadership for the Center of Faculty Excellence (CFE). She holds a Bachelor of Science in Nursing degree from Madonna University, a Master of Science in Nursing degree from the University of Phoenix, and a Doctor of Nursing Practice degree from Touro University. Over the course of her $30+$ year career, she has held a broad range of roles in nursing practice, education, and educational leadership. Email: LFillmore@chamberlain.edu

\section{REFERENCES}

American Association of Colleges of Nursing. (2014). Nursing shortage fact sheet. Washington, DC: Author.

Bain, K. (2004). What the best college teachers do. Cambridge, MA: Harvard University Press.

Bass, R. (2012). Disrupting ourselves: The problem of learning in higher education. Educause Review, March/April, 2012.

Benner, P., Sutphen, M., Leonard, V., \& Day, L. (2010) Educating nurses: A call for radical transformation. San Francisco, CA: 
Jossey-Bass.

Cohen, A.M., \& Kisker, C.B. (2010). The shaping of American higher education: Emergence and growth of the contemporary system. ( $2^{\text {nd }}$ ed.). San Francisco, CA: Jossey-Bass.

Dreyer, A., Couper, I., Bailey, R., Talib, Z., Ross, H., \& Sagay, A. S. (2015). Identifying approaches and tools for evaluating community-based medical education programmes in Africa. African Journal of Health Professions Education, 7(1), 134-139.

Felver, F., Gaines, B., Heims, M., Lasater, K., Lausten, G., Lynch, M., ...Tanner, C. (2010). Best practices in teaching and learning in nursing education. New York, NY: National League for Nursing.

Forneris, S. G., \& Fey, M. K. (2016). Critical conversations: The NLN guide for teaching thinking. Nursing Education Perspectives, 37(5), 248-249. doi: 10.1097/01.NEP.0000000000000069

Fritz, C. O., Morris, P. E., \& Richler, J. J. (2012). Effect size estimates: current use, calculations, and interpretation. Journal of Experimental Psychology: General, 141(1), 2.

Haji, F., Morin, M. P., \& Parker, K. (2013). Rethinking programme evaluation in health professions education: Beyond 'did it work?' Medical Education, 47(4), 342-351.

Halstead, J. (2007). Nurse educator competencies: Creating an evidence-based practice for nurse educators. New York, NY: National League for Nursing.

Halstead, J. (2009). Well-prepared faculty: Needed to achieve excellence in nursing education. In M. Adams \& T. Valiga (Eds). Achieving excellence in nursing education. (pp. 29-42). New York: National League for Nursing.

Hutchings, P., Huber, M.T., \& Ciccone, A. (2011). The scholarship of teaching and learning reconsidered: Institutional integration and impact. San Francisco, CA: Jossey-Bass.

Institute of Medicine (2003). Health professions education: A bridge to quality. Washington, DC: National Academies Press.

Institute of Medicine (2010). The future of nursing, leading change, advancing health. Washington, DC: National Academies Press.

Jasimuddin, S. M., \& Hasan, I. (2015). Organizational culture, structure, technology infrastructure and knowledge sharing. Vine, 45(1), 67-88. https://doi.org/10.1108/VINE-05-2014-0037

Jung, C. G. (1969).The structure and dynamics of the psyche. (R. F. C. Hull, Trans.), H. Read et al. (Eds.), The collected works of C. G. Jung: Vol. 8. (2 ${ }^{\text {nd }}$ ed.,). Princeton, NJ: Princeton University Press.

Kirkpatrick D. L. (1994). Evaluating training programs: The four levels. San Francisco, CA: Berrett-Koehler Publishers.

Lapkin, S., Levett-Jones, T., \& Gilligan, C. (2015). Using the Theory of Planned Behaviour to examine health professional students' behavioural intentions in relation to medication safety and collaborative practice. Nurse Education Today, 35(8), 935-940.

Leslie, K., Baker, L., Egan-Lee, E., Esdaile, M., \& Reeves, S. (2013). Advancing faculty development in medical education: A systematic review. Academic Medicine, 88(7), 1038-1045. . doi: 10.1097/ACM.0b013e318294fd29

McComish, D., \& Parson, J. (2013). Transformational learning and teacher collaborative communities. New Zealand Journal of Teachers' Work, 10(2), 239-245.

McDrury, J. \& Alterio, M. (2003). Learning through storytelling in higher education. London: Kogan Page.

McLaughlin, B. (2009). Qualified students: Needed to achieve excellence in nursing education. In M. Adams \& T. Valiga (Eds). Achieving excellence in nursing education. (pp. 103-114). New York: National League for Nursing.

National Academies of Sciences, Engineering, and Medicine. (2015). Assessing progress on the Institute of Medicine Report The Future of Nursing. Washington, DC: The National Academies Press.

National Research Council. Committee on Developments in the Science of Learning. (2000). How people learn: Brain, mind, experience, and school: Expanded Edition. Washington, DC: The National Academies Press.

Neal, E., \& Peed-Neal, I. (2010). Promoting your program and grounding it in the institution. In Gillespie, K. \& Robertson, D. (Eds). A guide to faculty development (99-115).

Opperman, C., Liebig, D., Bowling, J., Johnson, C. S., \& Harper, M. (2016). Measuring return on investment for professional development activities: Implications for practice. Journal for Nurses in Professional Development, 32(4), 176-184. doi: 10.1097/NND.0000000000000274

Sarikaya, O., Kalaca, S., Yegen B. C., \& Cali, S. (2010). The impact of a faculty development program: Evaluation based on the self-assessment of medical educators from preclinical and clinical disciplines. Advances in Physiology Education, 34(2), 35-40. doi: 10.1152/advan.00024.2010

Sabelli, N., \& Dede, C. (2013). Empowering design based implementation research: The need for infrastructure. Design-based implementation research: Theories, methods, and exemplars. National Society for the Study of Education Yearbook, $112(2), 464-480$.

Schaefer, K. M., \& Zygmont, D. (2003). Analyzing the teaching style of nursing faculty: Does it promote a student-centered or teacher-centered learning environment? Nursing Education Perspectives, 24(5), 238-245.

Schriner, C., Deckelman, S., Kubat, M.A., Lenkay, J., Nims, L., \& Sullivan, D. (2010). Collaboration of nursing faculty and college administration in creating organizational change. Nursing Education Perspectives, 31 (6), 381-386. doi: http://dx.doi.org/10.1043/1536-5026-31.6.381

Schroeder, C. M. (2011). Coming in from the margins: Faculty development's emerging organizational development role in 
institutional change. Sterling, VA: Stylus.

Shadiow, L. K. (2013). What our stories teach us: A guide to critical reflection for college faculty. San Francisco, CA: JosseyBass.

Sherwood, G. (2014). The scholarship of reflective practice. Indianapolis: Sigma Theta Tau Press.

Sherwood, G. \& Horton-Deutsch, S. (Eds.) (2012). Reflective practice: Transforming education and improving outcomes. Indianapolis: Sigma Theta Tau Press.

Sherwood, G., \& Horton-Deutsch, S. (2015). Reflective organizations: On the front lines of QSEN \& reflective practice implementation. Indianapolis: Sigma Theta Tau Press.

Steinert, Y. (2014). Faculty Development: Future Directions. In Faculty development in the health professions (pp. 421-442). Springer Netherlands.

Zheng, M., Bender, D., \& Nadershahi, N. (2015). Faculty professional development in emergent pedagogies for instructional innovation in dental education. European Journal of Dental Education. doi: 10.1111/eje.12180 
NOTES 